\title{
Common Hepatic Duct
}

National Cancer Institute

\section{Source}

National Cancer Institute. Common Hepatic Duct. NCI Thesaurus. Code C32356.

A component of the biliary duct system created by the convergence of the left and right hepatic ducts. 